\title{
DIAGNÓSTICO RÁPIDO PARTICIPATIVO NO LEVANTAMENTO DAS CAUSAS DE INCÊNDIOS FLORESTAIS NO CAMPUS DA UFLA ${ }^{1}$
}

\author{
Daniela D. V. Melo \\ Eduarda M. O. Silveira² \\ Maíra Dzedzej ${ }^{2}$ \\ José Aldo A. Pereira ${ }^{3}$
}

\begin{abstract}
RESUMO
No Campus da Universidade Federal de Lavras, MG, a estação de inverno é marcada por temperaturas e umidade relativa do ar baixas, e um por longo período seco. Neste período, um grande número de incêndios oriundos das comunidades vizinhas atinge o campus, particularmente as áreas de difícil acesso, o que prejudica o controle e uso de equipamentos básicos. O objetivo deste trabalho foi descrever a origem, causas e formas de controle dos incêndios. A metodologia utilizada foi o Diagnóstico Rápido Participativo - DRP, por meio de 12 entrevistas semi-estruturadas. Concluiu-se que não são realizadas queimadas controladas; houve aumento dos números de incêndios decorrentes da expansão urbana; há falta de manutenção dos aceiros e estradas; os maiores responsáveis são incendiários juvenis. Os principais problemas decorrentes dos incêndios relacionam-se ao abastecimento de água, toxidez da fumaça e presença de animais peçonhentos nas residências. O combate inicial é realizado pelos moradores locais.

Palavras chave: DRP; comunidades vizinhas; entrevistas semi-estruturadas
\end{abstract}

\section{PARTICIPATORY RAPID APPRAISAL IN THE RESEARCHING OF THE CAUSES OF FIRES AT UFLA'S CAMPUS}

\begin{abstract}
The winter season in the campus of the Federal University of Lavras, Lavras, Brazil, is characterized by lower temperatures and air humidity, and a long period of drought. During this period a high number of fires arising from the neighborhoods reach the campus, particularly those areas with more difficult access, bringing additional difficulties to fire control and use of basic equipments. The objective of this work was to describe the origin, causes and forms of fire control. The method used was the Participatory Rapid Appraisal - FPD, through 12 semi-structured interviews. The conclusions were that controlled fires are not carried out; there was an increase of the number fires resulting from urban expansion; there was a lack of maintenance of both fire-breaks and roads; the main responsible were young arsoners. The main problems arising from the fires are related to water supplying, smoke toxicity and the presence of the poisonous animals in residences. The initial combat is carried out by local inhabitants.
\end{abstract}

Keywords: FDP; neighborhood, semi-estructured interwiews

\section{INTRODUÇÃO}

Incêndio Florestal é todo fogo sem controle que incide sobre qualquer forma de vegetação (Soares, 1986; Couto e Cândido, 1980; Sarre e Goldammer, 1996) podendo tanto ser provocado pelo homem, intencionalmente, ou por negligência, ou ainda por fonte natural (Soares, 1986).

O combate a incêndios florestais é a estratégia de ação que visa após a identificação de um foco de fogo, que ele seja contido e eliminado, mediante a adoção de técnicas e equipamentos apropriados e pessoal treinado e capacitado para atuar no combate ao fogo (MMA, 1997).

Queimadas são práticas agropastoris ou florestais, nas quais o fogo é utilizado de forma controlada, atuando como fator de produção, ou ainda para eliminar excesso de material combustível presente no piso das florestas (Soares, 1986; Sant'Anna, Pereira,

\footnotetext{
${ }^{1}$ Universidade Federal de Lavras, Caixa Postal 37, CEP: 37200-000 - Lavras - MG, Brasil

2 Estudantes do curso de Engenharia Florestal, Universidade Federal de Lavras, Caixa Postal 37, CEP: 37.200-000 - Lavras - MG. duarteventura@hotmail.com; dudalavras@hotmail.com; mairafloresta@yahoo.com.br

${ }^{3}$ Prof. Adjunto do Departamento de Ciências Florestais da Universidade Federal de Lavras, Caixa Postal 37, CEP: 37.200-000 - Lavras MG.jaldo@ufla.br
} 
Borém, 2001).

Os incêndios florestais causam grandes prejuízos à biodiversidade, ao ciclo hidrológico e ao ciclo do carbono na atmosfera. Tais prejuízos reduzem os serviços ambientais que a floresta, mantida em seu padrão atual, poderia proporcionar ao planeta. Uma intensa freqüência de fogo numa mesma região, admitida a hipótese de troca de paisagem, pode levar a perda irreversível de parte dos recursos genéticos, antes mesmo de conhecer seu potencial (Uhl e Buschbacher, 1991; Dean, 1996).

Nos incêndios florestais a vegetação queima gerando pesadas nuvens de fumaça, prejudicando o tráfego aéreo, com o fechamento de aeroportos, e aumentando o risco de acidentes aéreos e rodoviários. Outro fator relevante é o alto teor de Dióxido de Carbono $\left(\mathrm{CO}_{2}\right)$ (Graça, 1997) e de partículas lançadas na atmosfera, as quais afetam a saúde da população, aumentando a ocorrência de doenças respiratórias (Silva, 1998).

Anualmente, no campus da Universidade Federal de Lavras (UFLA), são comuns os casos de incêndios florestais criminosos, nas áreas de reflorestamento com Pinus sp, Eucalyptus sp e principalmente pastagem, que se tornam de difícil controle na medida em que os recursos e o número de vigilantes da UFLA são insuficientes, sem preparo e os equipamentos são inadequados para se efetuar o combate.

O Diagnóstico Rápido Participativo (DRP) evita problemas decorrentes de pesquisas longas e caras, tais como coletar dados em excesso, recolher dados sem importância, produzir resultados tardios e inadequados e fraca participação da população local. Além disso, o DRP evita riscos de pesquisas rápidas (apenas rápida impressão da área), sem estrutura e procura superar distorções, através da recuperação de informações qualitativas (Whiteside, 1994; Alencar, 1999). Ainda, segundo estes autores, este tipo de diagnóstico proporciona uma aprendizagem mútua pesquisador-população, pois promovem uma interação de ambas as partes.

O objetivo deste trabalho foi levantar a origem, causas, freqüência e controle dos incêndios florestais no Campus da Universidade Federal de Lavras.

\section{MATERIAL E MÉTODOS}

A área de estudo $\left(21^{\circ} 14^{\prime} \mathrm{S}\right.$ e $45^{\circ} 00^{\prime}$ W) apresenta altitude média de 900 metros, clima $\mathrm{Cwb}$, conforme a classificação de Köppen, com período de seca (maio a agosto) e período chuvoso (novembro a março) (Castro Neto et al., 1980).

Para o desenvolvimento deste trabalho foram utilizadas técnicas da metodologia do Diagnóstico Rápido Participativo (DRP), através de entrevistas semi-estruturadas, aplicadas em 12 famílias residentes na circunvizinhança do campus da Universidade Federal de Lavras. Fez-se, ainda, uso dos laudos de registros do corpo de bombeiros da cidade de Lavras, produzidos quando acionados pela administração da UFLA, em socorro aos incêndios ocorridos no campus desta Universidade.

Para as entrevistas foram selecionados moradores residentes nas áreas mais próximas às ocorrências dos incêndios. Em campo, para facilitar o diagnóstico, foram utilizados roteiros previamente elaborados. Os dados coletados foram sistematizados e trabalhados utilizando-se o programa Word for Windows.

\section{RESULTADOS E DISCUSSÃO}

Nas 12 residências entrevistadas encontrou-se média de quatro pessoas por casa, constituídas, na sua maior parte de pai, mãe e dois filhos de idades variáveis. Para a composição da renda familiar em $70 \%$ das residências todos os membros contribuem na sua formação e, $100 \%$ dos entrevistados apresentam baixa escolaridade (primeiro grau incompleto). As principais atividades desenvolvidas pelos entrevistados são: criação de pequenos animais e produção de alimentos nos quintais das residências; fabricação de doces; serviços diversos, "bicos" e cinco $(42,5 \%)$ entrevistados são assalariados, dentre os quais dois (17\%) são funcionários da UFLA.

Conforme a tabela 1, o maior número de pessoas entrevistadas (quatro) foi encontrado na classe de idade de 31-40 anos; ausência de pessoas na classe de 51-60 anos e, 
as classes de maior idade (61-70 e 71-80anos), estão representadas por somente uma pessoa.

Os entrevistados dispõem de pequeno espaço nos seus quintais (tabela 2) para produção de alimentos. Dentre os entrevistados, sete $(58,3 \%)$ apresentam área total (área construída mais quintal) inferior a $600 \mathrm{~m}^{2}$. Foi observada ausência de quintais em três $(25 \%)$ residências.
No manejo dos quintais para a produção de alimentos (tabela 3), sete $(58,3 \%)$ residências utilizam o fogo como prática de produção, enquanto duas (17\%) não utilizam esta prática. Pode-se constatar que se faz uso do fogo nas duas residências (17\%) que apresentam os maiores quintais, ou seja, aquelas onde as áreas são superiores a $750 \mathrm{~m}^{2}$.

Tabela 1: Distribuição das pessoas entrevistadas por classes de idade

Table 1: Distribution of interviewed people per age class

\begin{tabular}{|c|c|c|c|c|c|}
\hline \multicolumn{6}{|c|}{ Faixa etária dos moradores entrevistados } \\
\hline $20-30$ & $31-40$ & $41-50$ & $51-60$ & $61-70$ & $71-80$ \\
\hline 3 & 4 & 3 & - & 1 & 1 \\
\hline
\end{tabular}

Tabela 2: Dimensões das residências entrevistadas, incluindo as áreas dos quintais

Table 2: $\quad$ Dimensions of interviewed relidences, including their backyards

\begin{tabular}{|c|c|c|c|c|c|c|}
\hline \multicolumn{7}{|c|}{ Dimensões $\left(\mathrm{m}^{2}\right)$ das residências entrevistadas } \\
\hline $\begin{array}{c}\text { Ausência de } \\
\text { quintais }\end{array}$ & $<150$ & $151-300$ & $301-450$ & $451-600$ & $601-750$ & $>750$ \\
\hline 3 & 2 & 2 & 2 & 1 & - & 2 \\
\hline
\end{tabular}

Tabela 3: Manejo dos quintais para produção de alimentos

Table 3: Backyard management for food production

\begin{tabular}{|c|c|c|}
\hline \multicolumn{3}{|c|}{ Uso do fogo para produção de alimentos } \\
\hline Não possuem quintais & Utilizam o fogo & Não utilizam o fogo \\
\hline 3 & 2 & 7 \\
\hline
\end{tabular}

No intervalo de tempo estudado, entre os anos de 2000 e 2003 (tabela 4), foram registrados 22 incêndios no campus da UFLA, nos quais houve necessidade de combate, com a presença do corpo de bombeiros da cidade de Lavras.

Analisando os dados de ocorrência de incêndios, registrados pelo corpo de bombeiros, pode-se observar um acréscimo progressivo no número de incêndios entre os anos de 2000 e 2003 , com pequeno recuo em 2002. No todo, as áreas mais atingidas foram as pastagens, com 13 ocorrências, e a vegetação restante (Eucalyptus sp, Pinus sp e nativas) apresentou o total de três ocorrências no período estudado. A grande incidência de incêndios ocorreu no ano de 2003, quando se observou um total de dez incêndios, sendo sete em áreas de pastagens, totalizando a queima de 5,62 hectares, os quais se devem, possivelmente, ao regime climático daquele ano, que foi excepcionalmente propício (baixa precipitação e altas temperaturas) para a ocorrência de grandes incêndios. $O$ corpo de bombeiros foi chamado para atuar no combate de $21(91,3 \%)$ ocorrências de incêndios e apenas dois deles $(8,7 \%)$ se extingui sozinho devido à ocorrência de chuvas.

Solicitados a opinar, os entrevistados disseram que a maior ocorrência do fogo nos últimos anos deve-se à imprudência dos incendiários que transitam pelas áreas. Esta opinião é corroborada por depoimentos de vigilantes do campus, os quais atribuem, ainda, parte da responsabilidade dos incêndios a jovens que transitam nas áreas periféricas da UFLA. A escassez de verbas por parte da Universidade para formação e manutenção de aceiros e estradas, também foi apontada por vigilantes e administradores do campus, como uma das causas importantes pela ocorrência de grande número de incêndios. Observações "in loco", efetuadas pelos autores deste trabalho corroboram estas afirmativas. 
Tabela 4: Ocorrência de incêndios no campus da UFLA entre os anos de 2000 a 2003

Table 4: Fire occurrence in the UFLA campus between 2000 and 2003

\begin{tabular}{|c|c|c|c|c|c|c|c|}
\hline Ano & \multicolumn{3}{|c|}{$\mathrm{N}^{\mathbf{0}}$ de Incêndios } & $\begin{array}{c}\text { Área total } \\
\text { queimada }\end{array}$ & \multicolumn{2}{c|}{$\begin{array}{c}\text { Forma de extinção do } \\
\text { incêndio }\end{array}$} \\
\hline & Eucalyptus $\mathrm{sp}$ & Pinus $\mathrm{sp}$ & Nativas & Pastagem & $\left(\mathrm{m}^{2}\right)$ & Sozinho & Combate \\
\hline 2000 & - & - & - & 1 & - & - & 1 \\
\hline 2001 & 2 & 1 & 2 & 2 & $* 6.800$ & - & 7 \\
\hline 2002 & - & 1 & - & 3 & $* * 8.000$ & - & 4 \\
\hline 2003 & 1 & 1 & 1 & 7 & $* * * 57.000$ & 1 & 9 \\
\hline Total & 3 & 3 & 3 & 13 & & 1 & 21 \\
\hline
\end{tabular}

$* 5.000 \mathrm{~m}^{2}$ referentes a um dos incêndios em pasto; $1.800 \mathrm{~m}^{2}$ referentes a um incêndio em Pinnus $\mathrm{sp} ; * * 8.000 \mathrm{~m}^{2}$ referentes a dois dos incêndios em pasto (uma área de $3.000 \mathrm{~m}^{2}$ e outra de $5.000 \mathrm{~m}^{2}$ ); $* * * 800 \mathrm{~m}^{2}$ referentes a um incêndio em Eucalyptus sp; $56.2000 \mathrm{~m}^{2}$ referentes a sete incêndios em áreas de pastagem, respectivamente de $3.000 \mathrm{~m}^{2}, 30.000 \mathrm{~m}^{2}, 1500 \mathrm{~m}^{2}, 4.200 \mathrm{~m}^{2}, 1.500 \mathrm{~m}^{2}, 10.000 \mathrm{~m}^{2}$ e $\left.6.000 \mathrm{~m}^{2}\right)$.

Os entrevistados apontaram que os principais problemas decorrentes dos incêndios relacionam-se com o abastecimento de água, toxidez da fumaça afetando a saúde, principalmente das crianças, e a presença de animais peçonhentos que se deslocam das áreas queimadas em direção às residências. Afirmaram, ainda, que o combate inicial tem sido realizado pelos moradores próximos às áreas queimadas e que utilizam água das residências e abafadores para os primeiros combates, improvisados e retirados das árvores existentes no campo. Também sugeriram que melhorias na infra-estrutura para a comunidade local entrevistada, tais como telefone, ônibus e segurança (rondas noturnas e maior fiscalização) melhorariam a segurança e os aspectos relacionados aos incêndios no campus.

\section{CONCLUSÕES}

Concluiu-se que não são realizadas queimadas controladas para diminuir a quantidade de material combustível no subbosque dos reflorestamentos; que há escassez de investimentos por parte da UFLA para a formação e manutenção de aceiros e estradas; que houve aumento no número de incêndios decorrentes da expansão urbana e da circulação de pessoas nas áreas periféricas, que cresceram perigosamente na direção do campus, sem que medidas e melhoria de infraestrutura fossem tomadas; e que, finalmente, associados ao rigor climático, os maiores responsáveis por grande número de incêndios no campus da UFLA são incendiários juvenis.

Considera-se este trabalho como um passo importante que pessoas da comunidade acadêmica da Universidade Federal de Lavras (alunos e professores) do DCF e da Disciplina Incêndios Florestais podem dar na realização da extensão e prestação de serviços à comunidade local e à própria Universidade.

\section{REFERÊNCIAS}

ALENCAR, R. Introdução à metodologia de pesquisa social. Universidade Federal de Lavras. 1999. 125p.

CASTRO NETO, P.; SEDIYAMA, G.; VILELA, E. A. Probabilidade de ocorrência de períodos secos em Lavras, Minas Gerais. Lavras: Ciência e Prática. 1980.

COUTO, E.A.; CÂNDIDO, E.A. Incêndios Florestais. Universidade Federal de Viçosa. 1980. 101p.

DEAN, W. A Ferro e Fogo. São Paulo: Companhia das Letras, 1996. 484p.

GRAÇA, P.M.L.A. Conteúdo de Carbono da Biomassa Florestal na Amazônia e Alterações após a Queima. Piracicaba: USP, 1997. 105p. Mestrado (Engenharia Florestal).

MMA. Programa Piloto para a Proteção das Florestas Tropicais do Brasil. Brasília, 1997. p. 113- 133 .

SANT'ANNA, C.M.; PEREIRA, J. A. A.; BORÉM, R. A. T. Prevenção e Combate a Incêndios Florestais. Lavras: UFLA/FAEPE, 2001. 88 p.

SARRE, A.; GOLDAMMER, J.G. Se quema la casa. Actualidad Florestal Tropical. v.4, n.1. 1996. 
Diagnóstico rápido participativo...

SILVA, R.G. Manual de Prevenção e Combate aos Incêndios Florestais. Brasília: Instituto Brasileiro do Meio Ambiente. 106p. 1998.

SOARES, R. V. Prevenção e controle de incêndios florestais. Ministério da Educação e Cultura. Módulo 1. Brasília. 1986.

UHL, C.; BUSCHBACHER, R. Queimada: corte que atrai. Ciência Hoje: Amazônia. 160p.

WHITESIDE, M. Diagnóstico Participativo Rápido Rural: manual de técnicas. Moçambique: Comissão Nacional do Meio Ambiente. 1994. 64p. 